\title{
Voltage Safety: High or Low?
}

\author{
R W Meggs* MEng PhD CEng MIMarEST SMIEEE MIET ${ }^{1}$ \\ O J Simmonds MEng MSc CEng CMarEng MIMarEST ${ }^{2}$
}

$B M T, U K$

* Corresponding Author. Email: Robert.Meggs@bmtglobal.com

\begin{abstract}
Synopsis
Legislators and ship operators are continually seeking cleaner ship operations. One route to achieving this is through some form of electric propulsion, which, when coupled to energy storage systems, can realise the goal of zero-emission operation. With electric propulsion, the propulsion load, in whole or in part, becomes another consumer to be supplied by the ship's electric power generation and distribution systems.

This leads to a considerable increase in the electrical power that must be generated and managed. As every ALevel student knows, power is the product of voltage and current. Any increase in the power generated must be achieved by an increase in voltage, or current, or both. To increase the current leads to greatly increased heating and requires heavier conductors, so the preferred option is to increase the voltage.

This raises the question of safety. There is a perception that high voltage (HV) systems are inherently 'more dangerous' than low voltage ( $\mathrm{LV}$ ) ones, but the Authors contend that it is meaningless to argue that one system is 'less safe' than the other since LV can kill just as effectively as HV. The real issue is that the practicalities and safety implications of HV and LV systems are different, although there are some points in common.

In this paper we shall review the hazards and safety implications peculiar to HV and to LV, and those common to both. In the process we shall review operational practices and how they apply to HV and LV systems on board current platforms. Finally, we shall examine whether there is any transfer between LV and HV concluding on how best practice can be applied to future platforms to provide a greater assurance of safety at system level.
\end{abstract}

Keywords: Voltage, Marine, Electrical Safety, Hazards, LV, HV

\section{Introduction}

For many decades, ships' power and propulsion plants have been segregated from each other. This paradigm leads to a relatively large number of fossil-fuelled prime movers operating concurrently and, frequently, at low loadings. In consequence, emissions of greenhouse gasses and particulates are high and so legislators, ship operators and owners are seeking cleaner ways to operate ships.

Recent years have seen the introduction of some form of electric propulsion where both the propulsion power and ship services power are produced by the same set of generators. The main efficiency saving offered comes from the ability to use multiple generators in a power station concept (Simmonds, 2014). This theory involves only running the number and type of generators required to meet the electrical load demand.

Broadly speaking, there are two models of electric propulsion: full electric and hybrid:

- In the full-electric model, the propulsive power is provided entirely by electric motors that drive the shafts directly.

- In the hybrid model the propulsive power is provided by electric motors working in concert with conventional internal combustion engines such as diesels or gas turbines.

In both cases, propulsion is regarded as an electrical consumer just like the usual ship's services such as engine auxiliaries, deck machinery and navigation equipment. Note that in the hybrid model, the propulsion motors and their converters may have the capability of operating as generators, driven by the main propulsion

1. Bob Meggs is a Senior Electrical Engineer at BMT Defence and Security Ltd. in Bath, where he has led consultancy projects on such topics as electric machine excitation, power electronics and partial discharge. He is currently involved in life extension assessment for ageing naval platforms, and concept design work. He was formerly a research officer at the University of Bath.

2. Oliver Simmonds is a Principal Engineer at BMT in Bath, UK. A Chartered Engineer, he has a background in both Mechanical and Electrical Engineering and has lead several major projects ranging from the delivery of a hybrid power and propulsion system for a Naval auxiliary vessel through to a wide range of technology studies and concept development work. 
diesels. The hybrid model offers an opportunity to improve utilisation of the prime movers, potentially as a response to the need for greater efficiency but also due to trends in increasing electrical load demand.

Transferring the propulsion load to the electrical power system, however, considerably increases the amount of electrical power that must be generated and distributed. This demands an increase in voltage, current, or both. Increased current leads to increased heating, which drives up the mass of copper required to carry it, so it is preferable to increase the voltage.

High voltage (HV) is defined as voltage in excess of 1,000 VAC or 1,500 VDC. It is interesting to note that HV for ships was first proposed over 100 years ago (McClaren, 1909). Then, as now, there were/are perceptions that HV is 'less safe' than LV. But power systems of any voltage can be lethal in the 'right' circumstances, particularly when enclosed in steel vessels that float in salt water. Put bluntly, LV can kill just as effectively as $\mathrm{HV}$, so it is pointless to argue that one system is 'less safe' than the other.

Other objections that have been raised against $\mathrm{HV}$ include:

- Increased volume and weight of HV equipment compared to LV;

- Perceived high acquisition cost of HV equipment;

- More rigorous regulatory regime.

As we shall see later, HV equipment can indeed be larger and heavier than that for LV at similar power levels, but the difference is not as great as may be imagined. The increased acquisition cost of HV plant may be offset by the lower mass of copper required for cabling and bus bars. Compared to a low voltage (LV) system, HV systems operate in a more rigorous regulatory environment. So the practicalities and safety implications of $\mathrm{HV}$ and LV systems are different, although there are many points in common.

Taken together and, noting that high power LV systems tend to operate at greater than normal distribution voltages (typically $690 \mathrm{~V}$ rather than $440 \mathrm{~V}$ ), hazard levels of LV have increased so that they are comparable with HV. There is thus a strong case for harmonising the regulations so that high power LV is treated in much the same way as HV.

In this paper we shall review the hazards and safety implications that are particular to $\mathrm{HV}, \mathrm{LV}$, and those common to both. We shall show that, for a given system power level, the cost, volume and weight difference between LV and $\mathrm{HV}$ is not a great as might be imagined. We shall start by reviewing the relative advantages and disadvantages of $\mathrm{HV}$ and LV systems and the hazards associated with each.

\section{Background}

In the 'traditional' segregated power and propulsion model, internal combustion engines are linked mechanically to the shafts to provide propulsion. A further suite of internal combustion engines drive electrical generators to provide electrical power to ship services. Depending on its size, a ship with segregated propulsion and generation plants might have a ship service electrical load in the order of $1-2 \mathrm{MWe}$. This can be easily supplied at $440 \mathrm{~V}$ by four diesel generators of, say, $500 \mathrm{kWe}$ each.

The full load current (FLC) of each $500 \mathrm{kWe}$ generator would therefore be about $810 \mathrm{~A}$. Three conductors per phase of $150 \mathrm{~mm}^{2}$ cable ( 9 conductors in total) would be adequate, so for every $10 \mathrm{~m}$ run the cable mass would be about $150 \mathrm{~kg}$. Based on a generator impedance ( $\mathrm{X}_{\mathrm{d}}$ ') $)$ of $9 \%$ the prospective short circuit (PSC) current would be in the order of $18 \mathrm{kA}$ (peak) $/ 9 \mathrm{kA}$ (symmetrical RMS) and so the PSC rating of the generator switchboards would be around $50 \mathrm{kA}$.

\subsection{Hybrid Propulsion System}

A ship with hybrid propulsion may require around 5 - 10 MWe for propulsion (higher propulsion power being supplied, when required, by internal combustion prime movers), in addition to the $1.5-2$ MWe for ship services. This could be supplied by, say, four generators of about $1.8 \mathrm{MWe}$ each. At $440 \mathrm{~V}$ the full load current of each generator would approach 3,000 A, which could demand as many as 10 conductors of $150 \mathrm{~mm}^{2}$ per phase (30 conductors in total); this would weigh about $500 \mathrm{~kg}$ for a $10 \mathrm{~m}$ run. The prospective short circuit levels would be in the order of $32 \mathrm{kA}$ (symmetrical RMS) for each $1.8 \mathrm{MWe}$ generator, leading to impractically high short circuit rating for the generator switchboards.

If the voltage is increased to $690 \mathrm{~V}$, the generator FLC would still be over 1,800 A. This would reduce the cable mass slightly, to about six conductors of $150 \mathrm{~mm}^{2}$ cable per phase (18 conductors in total); this would weigh about $300 \mathrm{~kg}$ for every $10 \mathrm{~m}$ run, but short circuit levels remain high at around $20 \mathrm{kA}$ (symmetrical RMS) per generator. 


\subsection{Full Electric Propulsion}

With full electric propulsion of, say, $20 \mathrm{MWe}$, plus $2 \mathrm{MWe}$ of ship service load, then four generators each rated to at least $5.5 \mathrm{MWe}$ would be required. At $440 \mathrm{~V}$, the FLC of each generator would be over 9,000 A, which is impractical in terms of the mass of copper and high short circuit levels. Even at $690 \mathrm{~V}$ the FLC would be in excess of 5,500 A per generator. But at $6.6 \mathrm{kV}$ the FLC per generator reduces to about $600 \mathrm{~A}$, leading to considerable reduction in the mass of copper in comparison to LV. The short circuit levels and arc flash hazard are also considerably reduced, to about $6 \mathrm{kA}$ (symmetrical RMS).

Indeed, with propulsion power of $6 \mathrm{MWe} \mathrm{HV}$ becomes attractive, although the precise breakpoint between LV and HV is not clearly defined. But it becomes more compelling with installed powers of about $6 \mathrm{MW}$ and above (Gramstadt, 1993).

\section{HV and LV: Pros and Cons}

As we have seen, HV is a key enabler for higher-rated hybrid and full electric propulsion plants, but there is a historical aversion to HV that seems to focus on three main areas, namely size and weight, cost, and safety.

\subsection{Weight and Volume}

One of the benefits of $\mathrm{HV}$ is reduce load current compared to LV at the same power level. This means that bus bars and cables can be smaller, with a consequent saving in the mass of copper (and hence cost). Nevertheless, switchboards for HV plant require greater creepage and clearance distances between bus bars; this drives up the volume of switchboard enclosures and terminal chambers. Larger enclosures are heavier and need larger compartments and since access to these compartments has to be restricted to authorised personnel only, this may have an impact on the overall layout of the vessel.

To gain an understanding of the relative weight and volume of items of HV and LV equipment, consider the putative hybrid drive system shown conceptually in Figure 1. We shall compare HV and LV versions of the same system using actual plant ratings taken from recent in-house development designs.

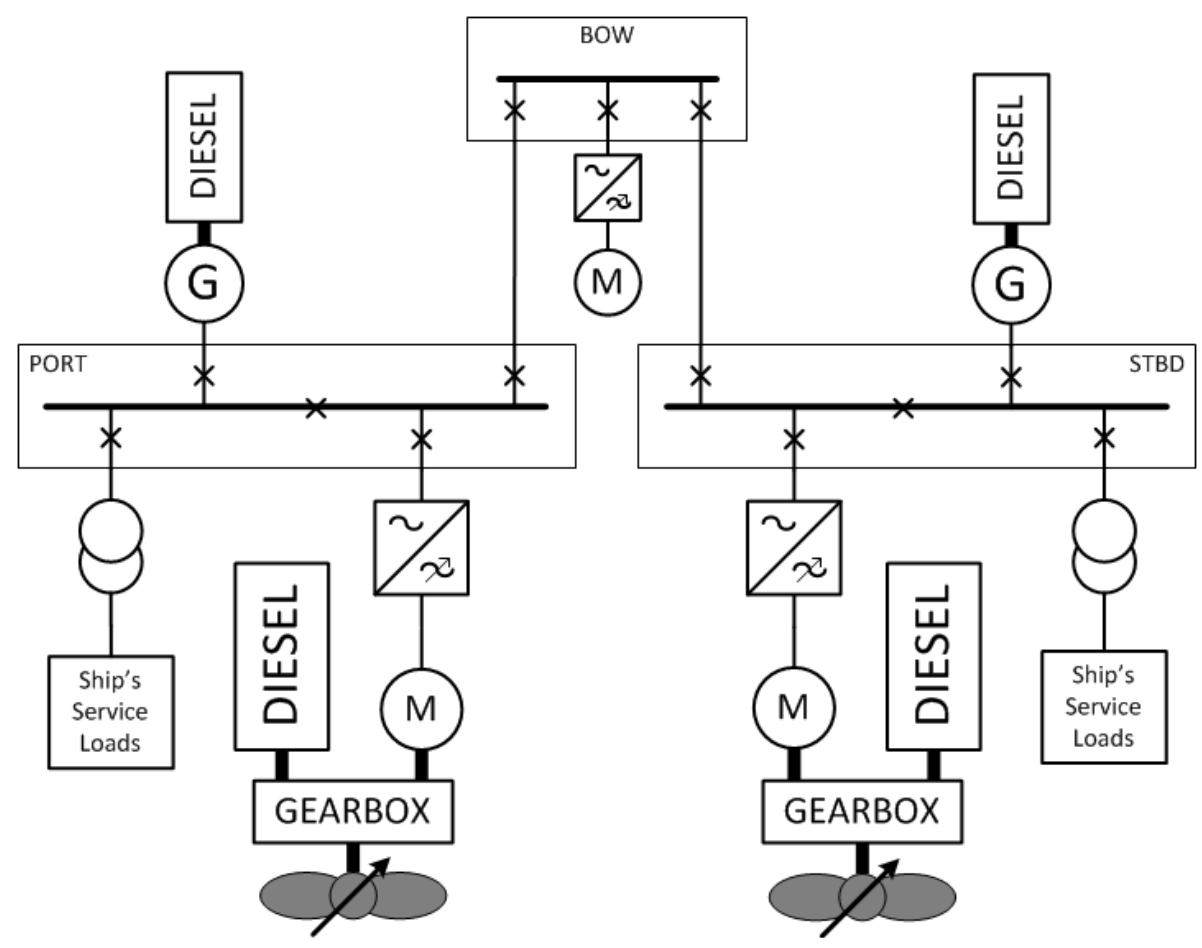

Figure 1: Putative hybrid drive system

Ratings of the main items of plant are summarised in Table 1. 
Table 1. Ratings of main items of equipment.

\begin{tabular}{lcc}
\hline \multicolumn{1}{c}{ Equipment } & LV Option [690 V] & HV Option [6.6 kV] \\
\hline Generator rated power [kVA] & 3,125 & 3,125 \\
\hline Main switchboards fault rating [kA] & 85 & 31.5 \\
\hline Aux switchboard fault rating [kA] & 85 & 31.5 \\
\hline Ship service transformer rating [kVA] & 3,000 & 3,000 \\
\hline AFE PTI/PTO converter rated power $[\mathrm{kW}]$ & 4,000 & 3,000 \\
\hline Hybrid Motor PTO power [kWe] & 2,460 & 2,460 \\
\hline Hybrid Motor PTI power [kW] & 1,000 & $<2,300$ \\
\hline Hybrid Motor speed range [RPM] & $600-1,200$ & $60-90$ (See note) \\
\hline Bow thruster converter rated power $[\mathrm{kW}]$ & 3,000 & 3,000 \\
\hline Bow thruster motor rated power $[\mathrm{kWb}]$ & 2,000 & 2,000 \\
\hline
\end{tabular}

Note: The HV option used a direct drive shaft mounted motor, whereas the LV option used a geared motor.

Table 2 shows the volumes of each main item of equipment for the LV and the HV versions of the hybrid drive. For most items, the HV equipment is larger than the LV items; this is expected as the greater creepage and clearance distances have driven the HV equipment up in size. But the overall size of the installation has only grown by about $27 \%$.

Table 2. All equipment volumes compared.

\begin{tabular}{lccc}
\hline \multicolumn{1}{c}{ Equipment } & No. Off & LV Option $\left[\mathbf{m}^{\mathbf{3}}\right]$ & HV Option $\left[\mathbf{m}^{\mathbf{3}}\right]$ \\
\hline Generator & 2 & 38.0 & 46.3 \\
\hline Main switchboards & 2 & 31.3 & 41.6 \\
\hline Aux switchboards & 1 & 12.9 & 16.5 \\
\hline Ship service transformer & 2 & 32.3 & 23.4 \\
\hline AFE PTI/PTO converter & 2 & 27.5 & 49.2 \\
\hline Hybrid Motor & 2 & 37.2 & 40.8 \\
\hline Bow thruster converter & 1 & 10.9 & 24.6 \\
\hline Bow thruster motor & 1 & 13.2 & 17.1 \\
\hline \multicolumn{2}{c}{ Total for all equipment: } & $\mathbf{2 0 3 . 4}$ & $\mathbf{2 5 9 . 6}$ \\
\hline & & $\mathbf{2 7 \%}$ larger
\end{tabular}

Similarly, a weight increase of about $8 \%$ can be expected in the HV installation, compared to the LV one (see Table 3).

Table 3. All equipment weights compared.

\begin{tabular}{lccc}
\hline \multicolumn{1}{c}{ Equipment } & No. Off & LV Option [kg] & HV Option [kg] \\
\hline Generator & 2 & 30,000 & 32,000 \\
\hline Main switchboards & 2 & 14,000 & 16,000 \\
\hline Aux switchboards & 1 & 6,000 & 6,500 \\
\hline Ship service transformer & 2 & 15,000 & 14,000 \\
\hline AFE PTI/PTO converter & 2 & 16,200 & 14,000 \\
\hline Hybrid Motor & 2 & 20,000 & 26,000 \\
\hline Bow thruster converter & 1 & 6,200 & 7,000 \\
\hline Bow thruster motor & 1 & 9,400 & 11,000 \\
\hline \multicolumn{2}{c}{ Total for all equipment: } & $\mathbf{1 1 6 , 8 0 0}$ & $\mathbf{1 2 6 , 5 0 0}$ \\
\hline
\end{tabular}




\subsection{Costs}

Significant cost savings in both acquisition costs and installation time at build can be made with a HV solution. For example, for a $3,125 \mathrm{kVA}$ generator at $6.6 \mathrm{kV}$ the rated current is about $342 \mathrm{~A}$, requiring three cores of $185 \mathrm{~mm}^{2}$ cable or 3 single cores of $150 \mathrm{~mm}^{2}$ in trefoil. For a generator of the same rating but at $690 \mathrm{~V}$ the rated current would be $3,269 \mathrm{~A}$, requiring 21 cores of $300 \mathrm{~mm}^{2}$ cable in 7 trefoil groups.

It is difficult to give actual costs due to the commercial considerations, but it has been found that the HV option allows equipment acquisition costs to be traded off against lower cable costs, both procurement and installation, and hence the overall cost of the HV system is only about $2 \%$ more costly than the equivalent highpower LV system.

\subsection{Safety}

As previously noted, there has been a perception that HV is 'less safe' than LV. This has led to a more rigorous regulatory regime than $\mathrm{LV}$, which is manifested in access controls on $\mathrm{HV}$ compartments, restrictions on the routing of $\mathrm{HV}$ cabling and crew competency requirements. But with the advent of high power LV systems fed at $690 \mathrm{~V}$ the hazards to personnel have increased due to the higher levels of short circuit current, arc flash and earth fault.

Historically, LV systems have been insulated earth (IT) types. In a true IT system, there is no intentional connection to earth (i.e. the hull) and so, theoretically, no current can flow in the hull in the presence of a single phase-to-earth fault. This gives a measure of resilience as the system can continue to operate in the presence of a single phase-to-earth fault.

In practice, however, there are always paths to earth, some unintended and some intentional. The unintended paths are formed mainly by parasitic capacitances and leakage resistance between cable conductors and the hull. The use of power-electronic converters and harmonic filters intentionally adds capacitance to shunt high frequency currents to earth. In HV systems, it is usual to earth the generator neutral points through a resistance that sets a known limit on the earth fault current.

To assure personnel safety, the earth fault current should be limited to less than $30 \mathrm{~mA}$; this is assured in the final domestic type electrical distribution with electrical protection solutions. In older ships with low power demand, this was easily achievable, but as power levels have increased so also has the amount of current that flows into the hull (Meggs, 2015) so that it is no longer possible to assure personnel safety in the presence of a single earth fault.

Furthermore, the higher short-circuit levels in high-power LV systems mean that the arc flash hazard is greatly increased, requiring further mitigations that may include restricting personnel from entering electrical equipment rooms; this is already done at $\mathrm{HV}$.

\section{Hazards}

A comprehensive list of all the hazards associated with electricity in the marine environment would include (in no particular order):

- Arc flash;

- Partial discharge.

- Electrocution (i.e. death from electric shock);

- Internal burns due to flow of current through the body;

- Burns from arc flash

- Injuries from machinery malfunctions;

- Secondary injuries from arc blast;

- Toxic substances such as PCBs, SF6, etc.;

- Bearing failure due to induced shaft currents;

- Insulation failure;

- Overtemperature and fire;

- Electrolytic action between dissimilar metals;

- Electromagnetic forces;

- Magnetic and voltage fields;

- Unintended electromagnetic couplings between items of equipment. 
These hazards are risks at all voltages, both LV and HV, but some are more dominant at either HV or LV. Space does not permit a full description of all known electrical hazards, so we shall focus on the first three from the list above, viz. arc flash, partial discharge and electric shock.

\subsection{Arc Flash - An LV Hazard}

Arc flash is a rapid release of energy caused by the uncontrolled flow of current between phases and ground. It can be initiated by events such as a short circuit or a switch being operated. The presence of contaminants, such as dirt or oil mist, inside a switchboard enclosure increase significantly the probability of an arc flash.

The energy released in an arc flash is proportional to the square of the arc current times its duration, so it is vital that the arc fault is cleared as quickly as possible. The impedance of the arc path is normally greater than that of typical short circuit paths, so the current being fed into the arc will be less than the expected short circuit current, but more than the normal load current. So the arc current is likely to be less than the short circuit (instantaneous) setpoint of the upstream protective device and hence the device will either fail to trip, or will take an extended amount of time to trip.

Short circuit levels tend to be greater in LV systems than in HV ones, so it follows that arc flash is a greater hazard in LV. Empirical methods exist that enable it to be estimated with reasonable accuracy. The most widely used methodology is specified in IEEE Standard 1584:2009.

We can apply the IEEE 1584 method for the three propulsion models were described earlier:

- Option 1: Mechanical propulsion with four $500 \mathrm{kWe}$ generators at $440 \mathrm{~V}$;

- Option 2: Hybrid propulsion with four $1.8 \mathrm{MWe}$ generators at $690 \mathrm{~V}$;

- Option 3: Full electric propulsion with four 5.5 MWe generators at $6.6 \mathrm{kV}$;

Note that, in each model, we posited that the ship's load would be up to 2 MWe. Applying the IEEE 1584 method to each of these options gives the following arc flash hazard levels:

- $\quad$ For Option 1 (bolted fault current about $18 \mathrm{kA}$ ): arc flash hazard ranges from $18 \mathrm{~J} / \mathrm{cm} 2$ (Category 2) to about $50 \mathrm{~J} / \mathrm{cm} 2$ (Category 3);

- For Option 2 (bolted fault current about $42 \mathrm{kA}$ ): arc flash hazard ranges from $72 \mathrm{~J} / \mathrm{cm} 2$ (Category 3 ) to $195 \mathrm{~J} / \mathrm{cm} 2$ (Category 5);

- For Option 3 (bolted fault current about $13 \mathrm{kA}$ ): arc flash hazard ranges from $11 \mathrm{~J} / \mathrm{cm} 2$ (Category 1) to $32 \mathrm{~J} / \mathrm{cm} 2$ (Category 2).

From this it can be seen that arc flash is predominantly a LV hazard.

\subsection{Partial Discharge - An HV Hazard}

Partial discharge (PD) is a failure mode described as "A localised electrical discharge that only partially bridges the insulation between conductors and which may or may not occur adjacent to a conductor" (IEC $60270,2001)$. It is frequently a symptom of the degradation of insulating materials, which, once initiated, can persist for long periods but eventually leads to failure of the insulation.

For any gas, there is a minimum voltage below which breakdown cannot happen. This was demonstrated in 1889 by Friedrich Paschen, who showed that the breakdown voltage of a gas is a non-linear function of its density and the strength of the electric field applied to it (Paschen, 1889). Since density is proportional to pressure and electric field strength is inversely proportional to the distance between the electrodes, it is more convenient to express breakdown voltage as a function of the product of the gas pressure and the distance between the electrodes. Figure 2 shows Paschen's curve for air at 1 bar, from which it can be seen that the minimum breakdown voltage is about $327 \mathrm{~V}$, which occurs at a distance of about $7.5 \mu \mathrm{m}$. This tells us that partial discharge in air cannot happen at less than $327 \mathrm{~V}$. 


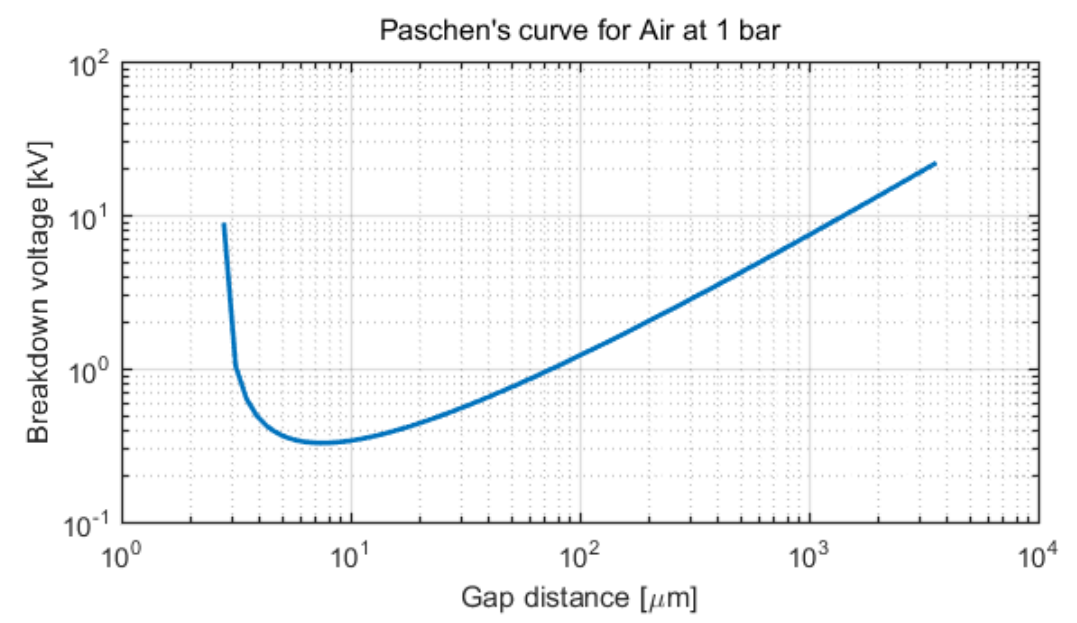

Figure 2: Breakdown voltage in air at 1 bar

In practice, arcing over small gaps, of the order of 0.1 to $1 \mathrm{~mm}$, between conductors can occur when there is potential difference of about $3 \mathrm{kV}$ or more at sea-level atmospheric pressure and hence PD is a hazard associated with HV.

\subsection{Electric Shock - Any Voltage}

Electrocution is defined as death by electric shock. It is a function more of the current through the body and the path it takes, rather than the applied voltage. Much of our knowledge of the effect of electric current on the human body comes from the work of Charles Dalziel in the 1950s and 1960s (Dalziel, 1972), which can be summarised as follows. The human body acts as a non-linear resistance, so that at low voltage $(<25 \mathrm{~V})$ its electrical resistance is relatively high (as high as $8,000 \mathrm{ohms}$ for dry skin at the point of contact). This has the effect of limiting the current to 'harmless' levels.

But at voltages in excess of 100 volts the body resistance drops to perhaps 4,000 ohms (or less if the skin is damp or wet) and so more current can flow. Above about $1,000 \mathrm{~V}$ the body resistance is substantially constant, about $1,000 \mathrm{ohms}$, and current in excess of $30 \mathrm{~mA}$ can flow. This is likely to cause permanent tissue or organ damage and lead to death. This is exacerbated as skin and tissue burns and becomes carbonised and therefore more conductive.

Thus electric shock is a hazard common to both HV and LV systems.

\section{Operational Practices}

The Ministry of Defence (MOD), like its contractors, is subject to both United Kingdom and European laws regarding Health and Safety at Work, without exemption. All Defence Standards either directly or indirectly invoke the use of processes and procedures that could be injurious to health if adequate precautions are not taken. Defence Standards or their use in no way absolves users from complying with statutory and legal requirements relating to Health and Safety at Work.

For HV, only competent (and trained) personnel are authorised to work on HV equipment and access to electrical compartments containing HV equipment are restricted to Competent Persons or higher and this is controlled by documentation (for example Limitation of Access, Permit to Work, Sanction for Test, etc.).

Access to LV on the other hand is generally less restricted, as LV equipment tends to be co-located with other equipment within general compartments on the ship. In addition there are much less regulations that cover access to and working on LV equipment.

High Power LV equipment (e.g. $690 \mathrm{~V}$ systems) technically come under LV legislation, and in many cases have been treated as such, even though we now know of the increased risks from the hazards. However some recent platform designs have started to adopt practices more akin to HV regulations: for example unmanned dedicated LV compartments for main switchboards, remote operating panels for the switching of breakers, and avoiding co-locating other non-electrical equipment within the main LV compartments. This 'adoption' of HV regulations for high power LV equipment is in effect becoming the norm, driven by the need for increased safety for both the operators and the systems themselves. 


\section{Conclusions}

In this paper, we started by noting the drivers for hybrid and full electric propulsion for ships, and that HV is a key enabler for high power electric propulsion. But there are objections to HV, mostly around size and volume, cost and safety. We have shown that, for a given power rating, there is an increase in size and weight of $\mathrm{HV}$ plant, but it is not excessive. Also, the increased procurement cost of HV equipment is offset by the reduction in cabling so that the cost differential is about $2 \%$.

From the safety perspective, we have shown that although the predominant hazards are different, HV is not 'less safe' than LV. Indeed, the hazards inherent in HV and high-power LV are, qualitatively, very similar. For example, due to the higher fault currents the arc flash hazard at LV is greater than that at HV. Conversely, at HV partial discharge is more of a hazard, although it can be used as the agent of its own diagnosis. Most other hazards, such as electric shock, are a risk at any voltage.

Historically, the less onerous regulatory framework that applies to LV has led to electrical equipment rooms being accessible to all personnel and used as offices and stores. This may have been acceptable for low power LV systems that were commonplace 20 - 30 years ago, but the higher risks of high power LV systems means that access controls similar to those in force for HV systems should be put in force.

\section{References}

European Standard IEC 60270 (2001): 'High-voltage test techniques - Partial discharge measurements', European Committee for Electrotechnical Standardization (CENELEC).

Dalziel, Charles F.: "Electric Shock Hazard”, IEEE Spectrum, February 1972.

Gramstadt, M.: "High Voltage on Passenger Vessels", Trans IMarE (TP) 1993, Vol 105, Part 1, Paper 1, pp1$1020-10-92$.

McClaren, J.: "The application of alternating currents of electricity in modern steamship requirements", Proceedings of the IMarE, March 1909.

Meggs, R.W.: "A Review of Earthing Methods for Low Voltage Power Systems”, MECSS Conference Proceedings, 2015.

Paschen, F.: "Ueber die zum Funkenübergang in Luft, Wasserstoff und Kohlensäure bei verschiedenen Drucken erforderliche Potentialdifferenz (On the potential difference required for spark initiation in air, hydrogen, and carbon dioxide at different pressures)", Annalen der Physik, vol. 273, Issue 5, pp.69-96, 1889.

Simmonds, O.J., 2014. "DC: Is it the Alternative Choice for Naval Power Distribution?", IMarEST International Naval Engineering Conference Proceedings, 20-22 May 2014, Amsterdam, The Netherlands. 